\title{
Pesticide poisoning deaths: a 19-year retrospective study of medicolegal autopsies in center Tunisia
}

\author{
Souheil Mlayeh', Khaled Annabi ${ }^{*}$, Amal Ben Daly², Maher Jedidi $^{2}$ and Mohamed Ben Dhiab²
}

\begin{abstract}
Background: Pesticide poisoning is recognized as an important public health problem worldwide, especially in the developing countries, such as Tunisia, where these products are massively used in agriculture. The objective of our study was to document the forensic deaths caused by pesticides reported from a forensic center located in the coastal region of Tunisia.

Methods: This is a 19-year retrospective descriptive study of lethal pesticide poisoning victims autopsied in the Department of Forensic Medicine at Farhat Hached University Hospital in Sousse, Tunisia, from 1991 to 2009.

Results: One hundred thirty deaths were collected. The majority of the victims were female (62\% vs $38 \%)$. The mean age was 27.46 years with the highest frequency of poisoning deaths occurring in the 21-30 years age group (34\%). Eleven percent of the victims were found in a state of coma and $4.6 \%$ suffered from respiratory distress. Signs observed during the external examination of the bodies were as follows: bluish discoloration of the lips and the limbs $(n=130,100 \%)$, leakage of urine $(n=13,10 \%)$, foaming at the mouth or the nose $(n=66,50.8 \%)$. The most frequent signs found during autopsies were pulmonary edema in $88.4 \%$ of the cases and multiorgan congestion in $86.9 \%$. Toxicological screening of the stomach content was positive for pesticides in 126 cases. Intoxication was mainly caused by cholinesterase inhibitor insecticides: carbamates (50\%) and organophosphorus compounds (31.5\%). In 92\% of cases, death was in a context of suicide.
\end{abstract}

Conclusions: This study shows that a large proportion of pesticide poisoning deaths are preventable. Prevention is, on the one side, by restricting the availability of pesticides and on the other side by promulgating more vigorous legislation concerning the manufacturing, the marketing, and the use of these products.

Keywords: Forensic science, Forensic toxicology, Forensic pathology, Pesticides, Poisoning death, Autopsy, Suicide

\section{Background}

Pesticide poisoning is responsible for overwhelming morbidity and mortality worldwide, especially in developing countries where these products are massively used in agriculture (World Health Organization and Food and Agriculture Organization of the United Nations, 2016). According to the World Health Organization (WHO), the incidence of pesticide poisoning is estimated between 1

\footnotetext{
* Correspondence: annabikhaled@gmail.com

'Department of Legal Medicine, Ibn El Jazzar University Hospital, 3100

Kairouan, Tunisia

Full list of author information is available at the end of the article
}

and 5 million victims with 300,000 lethal cases annually (World Health Organization and Food and Agriculture Organization of the United Nations, 2016). Thus, it is recognized as an important public health problem around the world (World Health Organization and Food and Agriculture Organization of the United Nations, 2016).

Pesticides can be classified according to their chemical properties as organophosphorus compounds (OP), carbamates, organochlorine compounds (OC), and chloralose (Yadav and Devi, 2017). OP and carbamates are the most widely used products and they account for the majority of lethal cases (World Health Organization and

\section{Springer Open}

() The Author(s). 2020 Open Access This article is licensed under a Creative Commons Attribution 4.0 International License, which permits use, sharing, adaptation, distribution and reproduction in any medium or format, as long as you give appropriate credit to the original author(s) and the source, provide a link to the Creative Commons licence, and indicate if changes were made. The images or other third party material in this article are included in the article's Creative Commons licence, unless indicated otherwise in a credit line to the material. If material is not included in the article's Creative Commons licence and your intended use is not permitted by statutory regulation or exceeds the permitted use, you will need to obtain permission directly from the copyright holder. To view a copy of this licence, visit http://creativecommons.org/licenses/by/4.0/. 
Food and Agriculture Organization of the United Nations, 2016).

Agriculture is one of the most important sectors in the Tunisian Economy (Trading economics 2019). It contributes up to $10 \%$ in the gross domestic product of the country (Trading economics 2019). To ensure the efficiency of this activity, pesticides are frequently used. Although there are specific laws regulating the use of pesticides in Tunisia, the insufficiency of the legislation and the lack of the application fail to prevent the indiscriminate use of these products.

Many studies carried worldwide emphasize the gravity of pesticide poisoning (Maria et al. 2006; Kahraman et al. 2008; Qian et al. 2009; Derkaoui et al. 2011; Idiz et al. 2012; Wang et al. 2019; Gummin et al. 2019). However, there are few studies reporting pesticide-poisoning-related deaths in Tunisia. Hence, this study aimed to document the forensic deaths caused by pesticides reported from a forensic center located in the coastal region of Tunisia between the years 1991 and 2009.

\section{Methods}

Located on the east coast of Tunisia, Sousse is the third biggest city in terms of population. The Department of Forensic Medicine at Farhat Hached University Hospital is the second major forensic Institute in Tunisia, serving Sousse and other cities located in the central region of Tunisia.

A retrospective descriptive 19-year review of data from 130 pesticide poisoning autopsies performed by the Department of Forensic Medicine at Farhat Hached University Hospital of Sousse between January 1, 1991, and December 31, 2009, was carried out. Data were obtained from judicial requisitions, autopsy reports, toxicology, and histology results. Judicial requisitions contained the identity of the victims and a brief description of the circumstances of death.

If the cause of death is apparent by scene investigation and review of clinical history, external examination is a general rule. All autopsy cases were subjected to comprehensive toxicology testing for pesticides, drugs, and alcohol. Specimens including blood, urine, and stomach contents were collected from each victim at autopsy. Pesticide poisoning was confirmed in these cases by analyzing the substance using thin-layer chromatography and gas chromatography-mass spectrometry at the Toxicology Department of Farhat Hached University Hospital.

This study was approved by the ethics committee of Farhat Hached University Hospital of Sousse, Tunisia.

\section{Results}

Between 1991 and 2009, 6812 autopsies were performed in the Department of Forensic Medicine at Farhat Hached University Hospital in Sousse, Tunisia. Three hundred and ten deaths $(4.5 \%)$ were attributed to lethal intoxication. Among them, 130 (41.9\%) were resulted from pesticide-poisoning. One hundred twenty-six of the cadavers were autopsied. The remaining 4 were patients hospitalized for a long duration in reanimation units with existing toxicology screening confirming the intoxication. Therefore, an external examination was sufficient.

The majority of the victims were female ( $62 \%$ vs $38 \%$ ). The mean age was 27.46 years with extreme ages between 8 months and 90 years. The highest frequency of poisoning deaths was in the 21-30 years age group (34\%).

Seventy-two percent of the victims $(n=94)$ lived in rural areas, $61.5 \%(n=80)$ were jobless, $76.1 \%(n=99)$ were single, and $13.8 \%(n=18)$ had a psychiatric history. The socio-demographic and medical characteristics of the victims are detailed in Table 1 .

The frequencies of pesticide-poisoning deaths according to the seasons of the year were as follows: summer $35 \%$, spring $26 \%$, winter $22 \%$, and autumn $17 \%$.

Eleven percent of the victims $(n=14)$ were found in a state of coma, $4.6 \%(n=6)$ suffered from respiratory distress, and $4.6 \%$ exhibited intense vomiting. Intoxication symptoms are detailed in Table 2 . The places where death occurred were $40 \%(n=52)$ in medical facilities, $27.6 \%(n=36)$ at home, $23.8 \%(n=31)$ during medical transportation, $5.3 \%(n=7)$ in public places, and 3\% $(n$ $=4)$ in the workplace. Twenty-one percent of the victims $(n=27)$ were hospitalized in intensive care units during 1 to 35 days with an average period of 5.84 days.

Signs observed during the postmortem external examination of the bodies were as follows: bluish discoloration of the lips and the limbs $(n=130,100 \%)$, leakage of urine $(n=13,10 \%)$, traces of vomiting over the clothes $(n=4,3.07 \%)$, foaming at the mouth or the nose $(n=66,50.8 \%)$, and traces of tongue biting $(n=5$, $3.84 \%)$. One victim had signs of recent sexual assault. The most frequent signs found during autopsies were pulmonary edema in $88.4 \%$ of the cases and multiorgan congestion in $86.9 \%$ (Table 3). The stomach content was green in 33 cases suggesting an intoxication with Lannate pesticide.

Toxicological screening of the stomach content was carried out in all the 126 autopsies and was positive for pesticides. Toxicology screening of urine was carried out in 90 cases and revealed chloralose intoxication in 14 cases. The anti-cholinesterase activity in the blood was measured in 107 cases and was normal in 9 cases (6.9\%), low in 4 cases $(3.1 \%)$, and very low in 94 cases $(72.3 \%)$. Carbamate insecticides were the main identified pesticides $(n=65,50 \%)$; the other products were OP insecticides $(n=41,31.5 \%)$, chloralose rodenticides $(n=18$, $13.8 \%)$, and OC insecticides $(n=2,1.5 \%)$. Methomyl was the main carbamate compound incriminated in poisoning deaths $(n=28,21.5 \%)$. The three identified OP 
Table 1 Sociodemographic and medical characteristics of the victims

\begin{tabular}{|c|c|c|c|}
\hline & Modality & $n$ & $\%$ \\
\hline \multirow[t]{2}{*}{ Sex } & Male & 49 & 38 \\
\hline & Female & 81 & 62 \\
\hline \multirow[t]{9}{*}{ Age } & $<10$ & 9 & 6.9 \\
\hline & $10-20$ years & 31 & 23.8 \\
\hline & 21-30 years & 44 & 33.8 \\
\hline & $31-40$ years & 22 & 16.9 \\
\hline & 41-50 years & 14 & 10.7 \\
\hline & 51-60 years & 5 & 3.8 \\
\hline & $61-70$ years & 1 & 0.7 \\
\hline & $71-80$ years & 2 & 1.5 \\
\hline & $81-90$ years & 2 & 1.5 \\
\hline \multirow[t]{2}{*}{ Origin } & Rural & 94 & 72 \\
\hline & From town & 36 & 28 \\
\hline \multirow[t]{4}{*}{ Marital status } & Single & 99 & 76.1 \\
\hline & Married & 23 & 17.6 \\
\hline & Divorced & 7 & 5.3 \\
\hline & Widowed & 1 & 0.7 \\
\hline \multirow[t]{3}{*}{ Occupation } & Jobless & 80 & 61.5 \\
\hline & Day laborer & 10 & 7.6 \\
\hline & Students & 40 & 30.7 \\
\hline \multirow[t]{2}{*}{ Medical history } & Psychiatric history & 18 & 13.8 \\
\hline & Neurological disorder & 7 & 5.3 \\
\hline \multirow[t]{3}{*}{ Nature of psychiatric disorder } & Depression & 12 & 9.2 \\
\hline & Schizophrenia & 1 & 0.7 \\
\hline & Behavioral disorders & 12 & 9.2 \\
\hline \multirow[t]{3}{*}{ Nature of the neurological disorder } & Mental retardation & 7 & 5.3 \\
\hline & Hemiplegia & 1 & 0.7 \\
\hline & Epilepsy & 5 & 3.84 \\
\hline
\end{tabular}

were dichlorvos, parathion, and Quickphos. Carbamazepine was found in the stomach content of 2 victims and haloperidol and phenobarbital in 2 other cases. Histological examination was carried out in 10 cases. It revealed pulmonary edema in 7 cases, acute broncho

Table 2 Symptoms of the intoxication

\begin{tabular}{lll}
\hline Symptom & $n$ & $\%$ \\
\hline Coma & 14 & 10.7 \\
Vomiting & 6 & 4.6 \\
Respiratory distress & 6 & 4.6 \\
Cardiac arrest & 5 & 3.8 \\
Convulsions & 4 & 3 \\
Malaise & 11 & 8.4 \\
Unknown & 84 & 64.6 \\
\hline
\end{tabular}

Table 3 Signs during autopsy

\begin{tabular}{lll}
\hline Sign & $n$ & $\%$ \\
\hline Multi-organ congestion & 113 & 86.9 \\
Cerebral edema & 46 & 35.3 \\
Pleural effusion & 12 & 9.2 \\
Pulmonary edema & 115 & 88.4 \\
Mucus in the bronchi & 69 & 53 \\
Ascites & 4 & 3 \\
Intestinal hemorrhage & 18 & 13.8 \\
Pregnancy & 3 & 2.3 \\
\hline
\end{tabular}

pneumopathy in 3 cases, multi-organ congestion in 6 cases, cerebral edema in 2 cases, and acute pancreatitis in 4 cases.

Pesticide poisoning deaths were due to suicide $(n=120$, $92.3 \%)$, followed by accidents $(n=8,6.1 \%)$, and homicide ( $n=2,1.5 \%)$. Familial conflicts were the triggering factor in $29.2 \%$ of the cases of suicide $(n=38)$. One male victim committed suicide after being sexually assaulted. Four infants were accidentally poisoned while they were playing.

\section{Discussion}

The present study revealed that the ratio of pesticiderelated deaths to all poisonings was $41.9 \%$. Similar ratios were observed in other agricultural producing countries. In China, for instance, Qian reviewed the records of 218 poisoning deaths from the Tongji Center for Medicolegal Expertise in Hubei, from 1999 to 2008 (Qian et al. 2009). He reported that $37.6 \%$ of toxic deaths were caused by pesticides. These cases are fewer in occidental countries. In fact, in the USA, pesticides were incriminated only in $3.47 \%$ of the cases of poisoning in 2018 (Gummin et al. 2019).

In the present study, the mean age of fatal pesticidepoisoning victims was 27.46 years. Kahraman et al. evaluated pesticide poisonings in a University Hospital in Turkey, from June 1, 1993, to June 31, 2007, and they reported that the mean age was 34.1 years (Kahraman et al. 2008). In the study of Derkaoui et al., reviewing 28 patients intoxicated with organophosphorus pesticides in Fès, Morocco, for 7 years between January 2003 and December 2010, the mean age was also young 24.5 years (Derkaoui et al. 2011). In fact, this period of age is associated with big social pressure for young adults leading to suicide by pesticide poisoning (Turecki et al. 2019). We found that $21 \%$ of intoxication victims were children aged under 18 years. Similarly, Maria et al. reported that $6.6 \%$ of the cases of poisoning in the state of Mato Grosso do Sul, Brazil, from 1992 to 2002, concerned children aged between 5 and 14 years (Maria et al. 2006). Pesticide poisoning among children is frequently accidental. In this period of age, children tend to explore the outside world and they interact with objects by putting them in their mouths (Gooch et al. 2016). 
A female predominance was observed in our study. Derkaoui et al. reported a similar rate of female victims (67\%) in Morocco (Derkaoui et al. 2011). This may be explained by the fragile attitude of women facing conflicts. It is also known that women hesitate and choose uncertain modalities of suicide such as pesticide poisoning compared to men who prefer more radical methods such as hanging (González et al. 2015).

As is the case in many studies, we have noticed that the majority of pesticide poisoning cases happened in rural areas (Maria et al. 2006; Kahraman et al. 2008; Qian et al. 2009; Derkaoui et al. 2011; Idiz et al. 2012; Wang et al. 2019; Gummin et al. 2019). This is mainly because pesticides are frequently used in agriculture. Furthermore, these regions are distant from medical facilities which make access to urgent medical assistance difficult. The low socioeconomic position and the poor educational level are also major risk factors (Idiz et al. 2013). In our study, $13.8 \%$ of the victims had a psychiatric history. Many studies emphasized on the role of psychiatric disorders in triggering suicide (Maria et al. 2006; Kahraman et al. 2008; Qian et al. 2009; Derkaoui et al. 2011; Idiz et al. 2012; Wang et al. 2019; Gummin et al. 2019).

Four victims were found in a state of coma. Coma is one of the most frequent signs of chloralose intoxication and it is generally profound (Richardson et al. 2019). Five percent of the victims exhibited respiratory symptoms. This is due to the bronchoconstriction and hypersecretion of mucus in the bronchi consequent to the muscarinic effect. OP may also, induce the paralysis of peripheral respiratory muscles when they interact with the nicotinic receptors and depress the central nervous respiratory centers (Nordgren and Bailey 2016).

Bluish discoloration of the lips and the limbs resulting from severe hypoxia was observed in all the victims. These signs are nonspecific of pesticide poisoning deaths and may be found in natural deaths. In our study, the most frequent signs discovered during autopsies were pulmonary edema and multiorgan congestion consequent to cardiac failure. Four victims had histological signs of acute pancreatitis. Yoshida et al. also reported cases of pancreatitis consequent to OP intoxication (Yoshida et al. 2015). Sixty-nine victims had abundant mucus in the bronchi. This is explained by the hyperactivity of the parasympathetic system induced by the intoxication (Mostafalou and Abdollahi 2017).

In our study, the most incriminated products were carbamate insecticides in $50 \%$ of the cases followed by OP insecticides in $31.5 \%$. Idiz et al. reviewed the deaths from pesticide poisoning occurring in Izmir, Turkey, from 2006 to 2009, and found that similar to our study carbamate insecticides were the major cause of death (Idiz et al. 2012). On the contrary, in the study of Wang et al. concerning pesticide poisoning in Jiangsu Province,
China, from 2007 to 2016, the number of poisonings by organophosphate pesticides was the highest $(18,548)$, accounting for $60.2 \%$ of all cases (Wang et al. 2019). Carbamates and organophosphates are anticholinesterase agents. Deaths are related essentially to respiratory disorders (Mostafalou and Abdollahi 2017). We found that only two victims were intoxicated with OC insecticides. This is due to the official ban of these products from commercialization (Strategic Approach to International Chemical Management (SAICM) Regional SAICM Implementation Report, 2012). Nevertheless, the Pesticide Action Network report estimates that an enormous stock of absolute OC products remains undestroyed explaining the occurrence of sporadic cases of intoxication with such compounds (Strategic Approach to International Chemical Management (SAICM) Regional SAICM Implementation Report, 2012). Eighteen victims in our study were poisoned with an alpha chloralose rodenticide. In the literature, few cases of chloralose poisoning have been reported (Maria et al. 2006; Kahraman et al. 2008; Qian et al. 2009; Derkaoui et al. 2011; Idiz et al. 2012; Wang et al. 2019; Gummin et al. 2019). Issifou analyzed 92 cases of fatal pesticide poisoning in the region of Sfax, south Tunisia, and found that chloralose poisoning represented $10.9 \%$ of the cases of pesticide intoxication deaths (Issifou 2004). The toxic dose of chloralose is $1 \mathrm{~g}$ among adults and $20 \mathrm{mg} / \mathrm{kg}$ among infants (Mostafalou and Abdollahi 2017). Deaths are essentially due to neurological disorders leading to coma (Mostafalou and Abdollahi 2017).

In the present study, suicide $(n=120,92 \%)$ was the most common manner of death followed by accidents $(n$ $=8,6.1 \%)$. In a previous study by Idiz et al, suicide was also the major method of death (43.8\%) (Idiz et al. 2012). In China, however, a retrospective study carried out in the Forensic Department of Tongi showed that poisoning was essentially accidental (Qian et al. 2009). One of the male victims in the current study committed suicide after being sexually assaulted. It is known that sexual assaults increase the risk of suicide (Mathilde et al., 2013). In our study, two infants aged 6 and 8 months were poisoned by their mothers. In the literature, criminal pesticide-poisoning cases are also rare. Helena et al., for instance, reported that homicide with pesticide poisoning represented only $1 \%$ of cases of toxic deaths (Helena et al. 2004).

The modalities of the use of pesticides are fixed by the $\mathrm{WHO}$ and the specific legislation of each country. In fact, the WHO defines each pesticide by its name, a number of the WHO standard, and the concentration of the active ingredient in its formula (World Health Organization and Food and Agriculture Organization of the United Nations, 2016). Class Ia includes extremely hazardous pesticides while class III is composed of 
slightly hazardous compounds. In Tunisia, law number 1961-39 promulgated on the 7th of July 1961, stipulates that pesticides cannot be commercialized without getting an official authorization from the authorities (Official Printing Office of The Republic of Tunisia 1961). Furthermore, this same law prohibits the conservation and the marketing of these products in facilities near food products. The 7th article of this same law also prohibits selling pesticides to children aged under 16 years. Moreover, law number 2010-2973 promulgated on the 15th of November 2010, states that in agriculture, pesticides must be used only by individuals with prior experience in pesticide management practices (Official Printing Office of The Republic of Tunisia 2010). It also insists that the nature of pesticides and the precautions for use must be clearly mentioned on the product package.

The restriction of the availability of pesticides and the promulgation of more strict legislation is known to be the most efficient preventive measures (World Health Organization and Food and Agriculture Organization of the United Nations, 2016) (Flemming et al. 2003). For instance, in the USA, the instauration of rigorous legislation concerning pesticide marketing and use reduced intoxication accidents significantly (Donley 2019). In the third world, the rigorous application of regulatory measures has also led to a significant decrease in pesticide-related mortality in several countries (Flemming et al. 2003). For example, the Department of Agriculture of Sri Lanka banned the use of fenthion and dimethoate, two class II pesticides, from June 2003. The comparison of the data 1 year before the ban (01 July 2002 until 30 June 2003) with 2 years after the ban (01 July 2004 until 30 June 2006) showed that hospital admissions for dimethoate and fenthion poisoning fell by $43 \%$. The pesticide case fatality fell from 14.4 to 9.0\% (Michael et al. 2012). Raising public awareness about the dangers of pesticides and the use of less toxic, equally effective alternatives were also factors contributing to the decrease in intoxication cases. In Tunisia, the prevention of pesticide poisoning started by the eradication of obsolete stocks of pesticides since 2005 as a part of the African Program on Obsolete Stocks of Pesticides (PASP-Tunisia program) (Strategic Approach to International Chemical Management (SAICM) Regional SAICM Implementation Report, 2012). This program aimed to reinforce the capacity of Tunisian institutions for rational management of chemicals, in general, and pesticides, in particular.

In Tunisia, there are two anti-poison centers, one in Tunis and the other in Sousse. The anti-poison centers (CAP) offer prevention and teaching activities. They provide appropriate toxicological information through constantly updated documentation, including the composition of the commercial products, their toxicity and the therapy to be implemented for each product concerned. These centers need to be developed nationally and regionally.

Globally, the International Code of Conduct on the Distribution and Use of Pesticides was enacted by the Food and Agriculture Organization of the United Nations (World Health Organization and Food and Agriculture Organization of the United Nations, 2016). It attempts to rationalize the use of pesticides and reduce the health and environmental risks associated with them. Its stated aim is to establish voluntary standards of conduct for all public and private entities engaged in or associated with the distribution and use of pesticides. The new version of the Code of Conduct adapts a "life-cycle" concept to address all stages from the development of products to the final disposal of containers (World Health Organization and Food and Agriculture Organization of the United Nations, 2016).

\section{Conclusions}

Pesticides are frequently used in agriculture and in homes. The availability and the easy access to these products make them a potential cause of death. Many studies have emphasized the gravity of acute pesticide poisoning but only few have described the findings during autopsies. Except for the discovery of the pesticide in the stomach content, no other signs during the autopsy were specific of pesticide poisoning. We have to underline that the frequency of pesticide poisoning is underestimated since many cases are incorrectly labeled as natural deaths. Hence, general practitioners and mainly pediatricians must be more attentive and request an autopsy whenever they suspect the context of intoxication. This study shows that a large proportion of pesticide poisoning deaths are preventable. Prevention is, on the one side, by restricting the availability of pesticides and on the other side by promulgating more vigorous legislation concerning the manufacturing, the marketing, and the use of these products.

\section{Abbreviations \\ OP: Organophosphorus compounds; OC: Organochlorine compounds; WHO: World Health Organization; PASP: African program on obsolete stocks of pesticides; CAP: Anti-poison centers; FAO: Food and Agriculture Organization}

\section{Acknowledgements}

None.

Adherence to national and international regulations Not applicable

\section{Authors' contributions}

All authors have equally participated in this work. All authors read and approved the final manuscript.

\section{Funding}

This research received no specific grant from any funding agency in the public, commercial, or not-for-profit sectors. 


\section{Availability of data and materials}

The datasets analyzed during the current study are available from the corresponding author on reasonable request.

\section{Ethics approval and consent to participate}

This study was approved by the ethics committee of Farhat Hached University Hospital of Sousse, Tunisia.

\section{Consent for publication}

Not required by the ethics committee.

\section{Competing interests}

The authors declare that they have no competing interests

\section{Author details}

'Department of Legal Medicine, Ibn El Jazzar University Hospital, 3100 Kairouan, Tunisia. ${ }^{2}$ Department of Legal Medicine, Farhat Hached University Hospital, Sousse, Tunisia.

Received: 22 January 2020 Accepted: 28 July 2020

Published online: 05 August 2020

\section{References}

Derkaoui A, Elbouazzaoui A, Elhouari N, Achour S, Labib S, Sbai H, Harrandou M, Khatouf M, Kanjaa N (2011) Severe acute intoxication by organophosphate pesticides: about 28 cases. Pan Afr Med J 8:16

Donley N (2019) The USA lags behind other agricultural nations in banning harmful pesticides. Environ Health 18, 44 (2019). https://doi.org/10.1186/ s12940-019-0488-0

Flemming K, Van der Hoekb W, Donald C, Gerard H, Hubert D, Surjit S (2003) Reducing acute poisoning in developing countries-options for restricting the availability of pesticides. Toxicology 192:249-261

González C, Thelma D, Yazmín Z, Carlos A, Krystell F, Rojop A, Isela N, Lilia S, Mario M (2015) Differences by gender in completed suicides in a Mexican population: a psychological autopsy study. J Forensic Leg Med:38. https://doi. org/10.1016/j.jflm.2015.11.019

Gooch D, Thompson P. Nash H.M, Snowling MJ, Hulme C (2016) The development of executive function and language skills in the early school years. J Child Psychol Psychiatry 57: 180-187. https://doi.org/https://doi.org/ $10.1111 /$ jcpp. 12458

Gummin DD, Mowry JB, Spyker DA, Brooks DE, Beuhler MC, Rivers LJ, Hashem HA, Ryan ML (2019) 2018 Annual Report of the American Association of Poison Control Centers' National Poison Data System (NPDS): 36th Annual Report. Clin Toxicol (Phila) 57(12):1220-1413. https://doi.org/10.1080/ 15563650.2019 .1677022

Helena T, Paula P, Margarida A, Margarida O, Estela PM, Duarte NV (2004) Pesticide intoxications in the centre of Portugal: three years analysis. Forensic Sci Int 143:199-204

Idiz N, Karakus A, Dalgıç M (2012) The forensic deaths caused by pesticide poisoning between the years 2006 and 2009 in Izmir, Turkey. J Forensic Sci 57(4):1014-1016 https://doi.org/10.1111/j.1556-4029.2012.02085

Issifou A (2004) Fatal pesticide poisoning: forensic study of 92 cases. University of Sfax

Kahraman N, Yantural S, Sule O, Nese H, Nil T (2008) Evaluating the relationship between serum acetylcholinesterase levels and clinical course and mortality of patients presented with organophosphate and carbamate poisonings. Turk J Emerg Med 8:121-126

Maria R, Dario P, Eloisa C (2006) Acute poisoning with pesticides in the state of Mato Grosso do Sul, Brazil. Sci Total Environ 357:88-95. https://doi.org/ https://doi.org/10.1016/j.scitotenv.2005.04.029

Mathilde MH, Romain G, François B, Grégory M (2013) Risk behaviors, suicidal ideation and suicide attempts in a nationally representative French sample. https://doi.org/10.1016/j.jad.2013.08.035

Michael E, Sriyantha A, Samitha E, Hasantha R, Fahim M (2012) Effects of a provincial ban of two toxic organophosphorus insecticides on pesticide poisoning hospital admissions. Clin Toxicol 50:3, 202-209. https://doi.org/ https://doi.org/10.3109/15563650.2012.660573

Mostafalou S, Abdollahi M (2017) Pesticides: an update of human exposure and toxicity. Arch Toxicol 91:549-599 https://doi.org/10.1007/s00204-016-1849-x

Nordgren TM, Bailey KL (2016) Pulmonary health effects of agriculture. Curr Opin Pulm Med 22(2):144-114 https://doi.org/10.1097/MCP.0000000000000247
Official Printing Office of the Republic of Tunisia. Official gazette $n^{\circ} 34$ of august 25, (1961). Law n ${ }^{\circ} 1961-39$ on controls on the marketing and use of pesticides for agricultural use

Official Printing Office of the Republic of Tunisia. Official gazette $n^{\circ} 94$ of November 23, (2010). Law n²010-2973 on the terms and the conditions for obtaining approval, provisional authorizations for the sale of pesticides for agricultural use

Qian L, Lan Z, Na Z, Luo Z, Yan L, Liang L (2009) Poisoning deaths in China: type and prevalence detected at the Tongji Forensic Medical Center in Hubei. Forensic Sci Int 193:88-94 https://doi.org/10.1016/j.forsciint.2009.09.013

Richardson JR, Fitsanakis V, Westerink RHS, Kanthasamy AG (2019) Neurotoxicity of pesticides. Acta Neuropathol 138(3):343-362 https://doi.org/10.1007/ s00401-019-02033-9

Strategic Approach to International Chemical Management (SAICM) Regional SAICM Implementation Report (2012) Available via DIALOG. https://ipen.org/ sites/default/files/documents/final\%20Francophone\%20Africa\%20SAICM\% 20regional\%20hub\%20implementation\%20report\%20for\%20web\%20English. pdf. Accessed 30th March, 2019

Trading economics (2019) https://tradingeconomics.com/tunisia/gdp-fromagriculture. Accessed 30 ${ }^{\text {th }}$ March ,2019.

Turecki G, Brent DA, Gunnell D, O'Connor RC, Oquendo MA, Pirkis J, Stanley BH (2019) Suicide and suicide risk. Nat Rev Dis Primers.5(1):74. https://doi.org/10. 1038/s41572-019-0121-0

Wang N, Jiang Q, Han L, Zhang H, Zhu B, Liu X (2019) Epidemiological characteristics of pesticide poisoning in Jiangsu Province, China, from 2007 to 2016. Sci Rep 9(1):8604 https://doi.org/10.1038/s41598-019-44986-7

World Health Organization \& Food and Agriculture Organization of the United Nations (2016) International code of conduct on pesticide management: guidelines on highly hazardous pesticides. https://apps.who.int/iris/handle/1 0665/205561. Accessed 7th March 2019.

Yadav, Ishwar \& Devi, Ningombam (2017) Pesticides classification and its impact on human and environment. Environmental science and engineering, Edition: Vol. 6: Toxicology, Chapter: 7, Publisher: Studium Press LLC, USA

Yoshida, S., Okada, H., Nakano, S. Shirai K, Yuhara T, Kojima H, Doi T, Kato H, Suzuki K, Morishita K, Murakami E, Ushikoshi H, Toyoda I, Ogura S (2015) Much caution does no harm! Organophosphate poisoning often causes pancreatitis. J Intensive Care 30;3(1):21. https://doi.org/10.1186/s40560-0150088-1

\section{Publisher's Note}

Springer Nature remains neutral with regard to jurisdictional claims in published maps and institutional affiliations.

\section{Submit your manuscript to a SpringerOpen ${ }^{\circ}$ journal and benefit from:}

- Convenient online submission

- Rigorous peer review

- Open access: articles freely available online

- High visibility within the field

- Retaining the copyright to your article

Submit your next manuscript at $\boldsymbol{\nabla}$ springeropen.com 